\section{Accuracy, statistics and fraud}

SIR-The catalogue of errors in scientific publications exemplified in the article by Stewart and Feder $^{1}$ will not surprise any statistician or biometrician, least of all one who has acted as a statistical referee of biological papers submitted for publication. Stewart and Feder refer to a paper ${ }^{2}$, where "almost all the data ... are contained in three figures which cannot be reconciled with each other", and this experience could be mirrored only too often.

Biometricians, and the Biometric Society, have been concerned with this problem for many years, an early example being the critical review by Mead and Pike $^{3}$. The British region of the society held a full-day meeting in December 1981 on "Statistical Presentation of Information in Biological Journals", where journal editors and statistical consultants put forward views that were discussed by a panel of experts and the audience. The British Medical Journal and the Journal of Ecology, representing very different areas of biology, were subjected to especial scrutiny. Although we believe the situation to have improved, there is still a long way to go. That the problem persists is shown by a letter ${ }^{4}$ that you published in the same week as the article by Stewart and Feder, where a biometrician criticized a paper for a simple arithmetical error.

The problem is not that there may be different possible statistical interpretations of the same data. Certainly there are different statistical techniques available for analysing the same data, and indeed there is a proliferation of computer packages that vary considerably in their statistical reliability. A statistical technique that I would not advocate could appear in a paper submitted to me as a referee: I might be slightly unhappy but, provided the interpretation was correct, I should not recommend rejection of the paper. Too often, however, as in the example quoted by Stewart and Feder, incorrect statistics mean that a paper is actually wrong. There is no need to postulate outright fraud. Sometimes authors genuinely do not understand their results - and this usually means that they have either not sought statistical advice or not made proper use of it. At other times, research workers will do an experiment to test a hypothesis and then, consciously or unconsciously, ignore results that do not conform to their preconceptions. With the pressure to publish, there is a tendency to cut corners.

It is wrong to blame only authors for making misleading statements ${ }^{1}$. Too many referees are insufficiently critical, and in-

Letters submitted for Correspondence should be typed, double-spaced, on one side of the paper only. deed too many editors do not seem aware of their responsibilities. The position might well be improved if you, sir, and your fellow-editors used referees who are able to distinguish minor weaknesses from substantial errors caused by inability to use correct statistical methods. The consequence might be fewer papers published, but those accepted would be of higher quality.

Statistical Consultancy Unit,

G.H. Freeman

University of Warwick,

Coventry CV4 7AL, UK

1. Stewart, W. W. \& Feder, N. Nature 325, 207-212 (1987)

2. Ann. Surg. 194, 189-192 (1981).

3. Biometrics 31, 803-851 (1975).

4. Perry, J. Nature 325, 202 (1987)

SIR-There is a serious methodological error in the paper by Stewart and Feder (Nature 325, 207; 1987), for there is no control group. Their own publications, submitted to independent assessors, could have fulfilled this role.

37 Upper Gordon Road,

A. M. W. Porter Camberley, Surrey GU15 2HJ, UK

SIR-Two recent papers have significant bearing on an important issue discussed in Nature recently $(325,207 ; 1987)$, namely the integrity of the scientific literature and specifically the problem of "scientific fraud".

In the first of these papers ${ }^{1}$, de Lacey and his colleagues asked the question, "How accurate are quotations and references in medical journals?" Their depressing answer was - not very! "...the original author was misquoted in $15 \%$ of al references, and most of the errors would have misled readers. Errors in citation occurred in $24 \%$, of which $8 \%$ were major errors - that is, they prevented immediate identification of the source of the reference."

In the second paper $^{2}$, I tried to assess the occurrence and the significance of 'self-confessed' errors in the biological literature, that is those instances where authors subsequently admit that something they had earlier published had not actually happened the way they originally said it had.

Again, the result of this survey was depressing. In a number of biological journals, including acknowledged leading journals, some 2 per cent of all papers are subsequently modified by their authors. While many of these modifications are primarily cosmetic, perhaps half of them are highly significant - 'we didn't actually use the buffer, drug, concentration, machines settings, number of animals,...' we originally said we did.

The number of such admissions may seem to be small, but how many such mis- takes, all of which render impossible the repetition of the work as originally published, are not detected ... or not admitted ... or not published?

At question is a fundamental point, the 'accuracy' of the published paper; all of us - readers, reviewers, editors - have to believe that what was reported did in fact take place.

Fraud, that is, a deliberate intention to mislead, which is (it is to be hoped) only rare, will account for some inaccuracies. But it also seems that a lack of sufficient care may be widespread and is responsible for many more inaccuracies. We readily and rightly condemn the fraudulent, but the end result from the activity of the careless is equally damaging to the framework, the reputation and the progress of science. Should not the careless be equally condemned, and carelessness guarded against with a vigour equal to that with which we guard against fraud?

JOHN R. SABINE

University of Adelaide,

Waite Agricultural Research Institute, Glen Osmond, South Australia 5064

1. de Lacey, G., Record, C. \& Wade J. Br. med. J. 291, 884 886 (1985)

2. Sabine, J.R. Bioscience 35, 358-363 (1985).

\section{Dissent in Singapore}

SIR-I should like to point out some errors in the letter "Dissent disallowed in Singapore" by Louis Mahadevan (Nature 324 298; 1986).

Firstly Mr J. B. Jeyaretnam was gaoled not for being "the voice of dissent in Singapore" but on a criminal offence. Jeyaretnam and Mr Wong Hong Toy were fined and gaoled for making a false declaration about their political party's accounts. Both Jeyaretnam and Wong appealed to the Privy Council, which dismissed the appeal with costs. Is Mahadevan questioning the integrity and independence of the Privy Council?

Second, Mahadevan alleged that the voice of dissent in Singapore is to be silenced at any cost. Far from it. Jeyaretnam has continued to voice his dissent during and since his gaol term through local as well as foreign publications circulated in Singapore.

Third, Mahadevan alleged that two publications were sanctioned for reporting Jeyaretnam's imprisonment and consequent loss of seat in Parliament. This is not true. The Asian Wall Street Journal was cited for contempt of the judiciary and apologized in court. Time magazine was sanctioned because it refused to publish corrections of errors in its article; it eventually admitted the errors and printed the corrections.

Mary Seet-Cheng (Acting High Commissioner)

Singapore High Commission, 2 Wilton Crescent, London SW1, UK 